\title{
Vasculites Associadas ao Anticorpo Anticitoplasma de Neutrófilo (Anca)
}

\section{Vasculitides Associated to Antineutrophil Cytoplasmic Antibodies (Anca)}

\author{
Boris A. Cruz ${ }^{(1)}$
}

\begin{abstract}
Vasculites associadas ao anticorpo anticitoplasma de neutrófilo (Anca) são um grupo de doenças caracterizadas histologicamente por vasculite necrotizante de vasos de pequeno calibre. Outra característica marcante é a ausência (ou rara presença) de depósitos de imunocomplexos nos vasos afetados em análises por imunofluorescência. Tal grupo inclui a granulomatose de Wegener, a síndrome de Churg-Strauss, a poliangiíte microscópica e sua variante limitada ao rim - glomuronefrite rapidamente progressiva (crescêntica) idiopática. São doenças raras e, até há pouco tempo, sua abordagem se baseava em decisões empíricas que variavam nos diferentes centros que se propõem a tratá-las. No entanto, nos últimos anos, grupos de colaboração e projetos multicêntricos, por meio de estudos com maior casuística, vêm sendo capazes de estabelecer diretrizes para melhor classificação e terapêutica desses pacientes. Esse desenvolvimento tem repercussão prática no prognóstico dessas doenças, na medida em que o conhecimento mais difundido permite diagnóstico mais precoce e tratamento mais eficaz. Esta seção traz artigos recentes produzidos pelo grupo europeu de estudo das vasculites (Euvas), pelo grupo francês de estudo das vasculites e por projetos multicêntricos que incluem centros de referência também dos Estados Unidos.
\end{abstract}

Kallenberg CGM: Antineutrophil cytoplasmatic autoantibody-associated small vessel vasculitis (Vasculite de vasos de pequeno calibre associadas ao Anca). Curr Opin Rheumatol 19: 17-24, 2007. Departamento de Reumatologia e Imunologia Clínica; Centro Médico Universitário de Groeningen, Groeningen, Holanda.

Neste artigo de revisão, o autor faz comentários sobre a patogênese e a classificação das vasculites associadas ao Anca. No entanto, a maior contribuição desse manuscrito está na revisão dos resultados dos ensaios clínicos multicêntricos mais recentes. Inicialmente, o estudo europeu CYCARAZEM demonstrou que a ciclofosfamida pode ser substituída pela azatioprina como tratamento de manutenção após indução com o agente citostático, sem perda de eficácia e com melhor perfil de tolerância. Para a indução de remissão, a ciclofosfamida oral pode ser substituída por ciclofosfamida endovenosa intermitente (pulsoterapia). Um ensaio clínico controlado (CYCLOPS) foi completado recentemente e os dados são aguardados para confirmar tal raciocínio. Em pacientes com granulomatose de Wegener sem envolvimento renal, particularmente aqueles com envolvimento limitado às vias aéreas superiores, o metotrexato (20-25 mg/semana) pode ser usado como terapia inicial no lugar da ciclofosfamida. O ensaio clínico controlado NORAM demonstrou que o metotrexato é tão eficaz quanto a ciclofosfamida em pacientes sem perda de função renal e sem envolvimento orgânico mais grave. No entanto, um maior índice de recidiva após o término (12 meses) do tratamento confirma que esses pacientes precisam de tratamento imunossupressor mais longo. A despeito desses dados, cerca de $20 \%$ dos pacientes apresentam resposta insatisfatória ao uso de ciclofosfamida e outros imunossupressores. Tal fato levou à investigação de outras modalidades de tratamento em pacientes com doença potencialmente fatal. O ensaio MEPEX comparou a adição de corticóide em pulsoterapia ou plasmaférese à ciclofosfamida como tratamento de indução em pacientes com insuficiência renal aguda na apresentação da doença. Os resultados preliminares sugerem que a adição de plasmaférese leva à maior sobrevida renal após seis meses de evolução, ainda que a mortalidade tenha sido alta nesse ensaio. A terapia biológica também foi estudada em pacientes com vasculite. O ensaio clínico WGET avaliou o uso de etanercepte em pacientes com granulomatose de Wegener e não pôde demonstrar superioridade deste agente anti-TNF ao tratamento convencional. No entanto, limitações metodológicas foram levantadas nesse estudo. Dados preliminares sugerem que infliximab e rituximab podem ser de valia em pacientes com doença refratária ao tratamento usual, mas resultados mais definitivos de ensaios clínicos de maior porte são aguardados. 
Weidner S, Hafezi-Rachti S, Rupprecht HD: Thromboembolic events as a complication of antineutrophil cytoplasmic antiboby-associated vasculitis (Eventos tromboembólicos como complicação de vasculites associadas ao Anca). Arthritis Rheum (Arthritis Care Res) 55: 146-9, 2006. Departamentos de Reumatologia da Universidade Ludwig-Maximilian, Munique, e da Universidade de Erlangen-Nürnberg, Erlangen, Alemanha.

Com a intenção de avaliar a importância relativa de eventos tromboembólicos venosos como complicação de vasculites associadas ao Anca, os autores estudaram a freqüência de trombose venosa profunda em uma série de casos retrospectivamente. Essa série de pacientes $(\mathrm{n}=105)$ incluiu pacientes com granulomatose de Wegener, poliangiíte microscópica e vasculite restrita ao rim acompanhados na Universidade de Erlangen entre 1984 e 2001. Destes, 13 pacientes apresentaram trombose venosa profunda na "fase ativa" da vasculite, ou seja, quando do diagnóstico, antes de qualquer tratamento específico. Dez pacientes $(76 \%)$ apresentavam anticorpo antiproteinase 3, e três (24\%) apresentavam antimieloperoxidase. Quanto ao diagnóstico, oito apresentavam granulomatose de Wegener; três, poliangiíte microscópica; e dois, vasculite limitada ao rim. Nesse grupo de pacientes, 12 apresentaram trombose venosa profunda em membros inferiores e seis apresentaram tromboembolismo pulmonar, sendo que, destes, dois foram a óbito por tromboembolismo pulmonar maciço. Nesta casuística, nenhum paciente apresentava fatores de risco conhecidos para tromboembolismo venoso, como repouso, cirurgia, neoplasia ou trombofilia hereditária ou adquirida. Após a fase aguda da vasculite, tromboembolismo venoso ocorreu em outros dois pacientes. No total, ocorreram 16 eventos tromboembólicos venosos em 367,5 pessoas-ano de observação. A incidência foi, então, de 4,3 eventos por 100 pessoas-ano, o que é notadamente maior do que a incidência esperada na população geral $(0,38$ eventos por 100 pessoas-ano) e mesmo em uma coorte de pacientes com lúpus eritematoso sistêmico $(0,98$ eventos por 100 pessoas-ano). Os autores entendem que eventos tromboembólicos venosos são uma complicação relativamente freqüente de vasculites associadas ao Anca. Ainda que esse dado necessite de confirmação em estudos prospectivos, é sugerido que o diagnóstico de trombose venosa deva ser avaliado rotineiramente em pacientes na fase ativa de vasculites associadas ao Anca, notadamente em pacientes com granulomatose de Wegener e/ou positividade para anticorpos antiproteinase 3 .

Flossmann O, Jones RB, Jayne DRW, Luqmani RA: Should rituximab be used to treat antineutrophil cytoplasmic antibody associated vasculitis? (Rituximab deve ser usado para tratar vasculite associada ao Anca?). Ann Rheum Dis 65: 841-4, 2006. Centro de Pesquisa Botnar da Universidade de Oxford, Oxford, Reino Unido.

Neste editorial, os autores avaliam os dados disponíveis na literatura médica quanto ao uso do rituximab para o tratamento de vasculites associadas ao Anca. O rituximab é um anticorpo quimérico anti-CD20 que leva à destruição de linfócitos B através de citotoxicidade celular, lise mediada por complemento e indução de apoptose. Inicialmente desenvolvido para tratamento de algumas formas de linfoma, o rituximab vem se mostrando eficaz em artrite reumatóide e em uma séria de outras doenças auto-imunes associadas a auto-anticorpos patogênicos, como lúpus eritematoso sistêmico e anemia hemolítica. Vasculites associadas ao Anca são caracterizadas por auto-anticorpos direcionados à proteinase 3 ou mieloperoxidase. Estudos experimentais e ensaios clínicos respaldam a importância desses anticorpos na patogênese e na manutenção da vasculite nesses pacientes. Teoricamente, o uso de rituximab em pacientes com vasculite associada ao Anca seria capaz de interferir com a reconstituição de plasmócitos e levaria à interrupção da produção desse anticorpo. Os autores têm o cuidado de descrever que a experiência com o uso desse anticorpo monoclonal em vasculites associadas ao Anca está restrita a pequenas séries de caso. No entanto, esses estudos incluíram casos refratários ou intolerantes aos tratamentos usuais. Em conjunto, $44 / 53$ pacientes ( $83 \%)$ alcançaram remissão completa e outros três, remissão parcial. Quatorze desses pacientes apresentaram recidiva entre nove e 21 meses, e alguns desses foram retratados com resultados excelentes na maioria dos casos. As recidivas seguiram a reconstituição de linfócitos $\mathrm{B}$ e usualmente se associaram à elevação dos títulos de Anca. Algumas manifestações clínicas se mostraram menos suscetíveis a esse tratamento, como inflamação granulomatosa retrorbital. Outra limitação importante reside no fato de a resposta plena poder demorar até três meses após a infusão, o que não seria aceitável em pacientes com doença de progressão mais rápida, o que é comum em vasculites associadas ao Anca. No que diz respeito à segurança, os efeitos adversos se resumiram a reações infusionais leves. É importante destacar que esse tipo de análise não 
se presta a determinar diretrizes de tratamento ou fornecer recomendações específicas. No entanto, os resultados preliminares são realmente promissores. No momento, dois ensaios clínicos avaliam de maneira mais eficiente o papel desse anticorpo monoclonal em vasculites associadas ao Anca. Nas palavras dos autores deste editorial, resta saber se essa nova modalidade de tratamento vai validar a boa expectativa que esses dados preliminares sugerem e se confirmar como alternativa de tratamento eficaz e segura para as vasculites associadas ao Anca.

Yu F, Huang JP, Zou WZ, Zhao MH: The clinical features of anti-neutrophil cytoplasmic antibody-associated systemic vasculitis in chinese children (Aspectos clínicos de vasculites sistêmicas associadas ao Anca em crianças chinesas). Ped Nephrol 21: 497-502, 2006. Departamento de Nefrologia da Universidade de Pequim, Pequim, China.

Vasculites associadas ao Anca ocorrem predominantemente em adultos, sendo seu pico de incidência a partir dos 60 anos. No entanto, podem acometer crianças. Neste trabalho, os autores descrevem as características de crianças com vasculites associadas ao Anca que foram acompanhadas em seu serviço. Vinte crianças com idade entre 6 e 14 anos (média 10,8 anos) com poliangiíte microscópica $(\mathrm{n}=19)$ e granulomatose de Wegener $(\mathrm{n}=1)$ são descritas. Dezenove pacientes apresentaram positividade para anticorpo antimieloperoxidase e apenas um apresentou anticorpo antiproteinase 3 . O tempo até o diagnóstico foi em média 8,5 meses, podendo chegar a nove anos. A maior parte das crianças apresentava envolvimento de mais de um órgão ou sistema. Como se trata de um serviço de nefrologia, nessa casuística todas as crianças apresentaram envolvimento renal. Destas, $16(80 \%)$ apresentaram insuficiência renal aguda. A despeito do tratamento que incluiu corticóide e imunossupressores, 10 (50\%) evoluíram para insuficiência renal terminal. Os autores argumentam que, ainda que a apresentação clínica seja similar à dos adultos, o atraso no diagnóstico pode ter contribuído para tal número de pacientes com insuficiência renal. O entendimento de que vasculites associadas ao Anca podem também ocorrer em crianças deve permitir o diagnóstico mais precoce e seu tratamento agressivo, podendo influenciar a sobrevida renal desses pacientes.

Hogan SL, Falk RJ, Chin H, Cai J, Jennette CE, Jennette JC, Nachman PH: Predictors of relapse and treatment resistance in antineutrophil cytoplasmic antibody - associated small-pessel vasculitis (Preditores de recidiva e refratariedade ao tratamento em vasculites de pequenos vasos associadas ao Anca). Ann Intern Med 143: 621-31, 2005. Universidade da Carolina do Norte em Chapel Hill, Chapel Hill, EUA.

Neste estudo, os autores se valeram de uma coorte de pacientes organizada a partir de um grupo de colaboração de doenças glomerulares. Trezentos e cinqüenta pacientes com diagnóstico de vasculite associada ao Anca entre 1985 e 2003 foram estudados. Os pacientes foram categorizados de acordo com dados demográficos, sorológicos e histológicos, e a relação dessas diferentes características com refratariedade e/ou recidiva da doença foi analisada. No que diz respeito à evolução, dos 350 pacientes inicialmente arrolados no estudo, 16 já apresentavam insuficiência renal terminal no início do seguimento e não receberam tratamento imunossupressor. Dos 334 pacientes restantes, 76 (23\%) apresentaram progressão da doença a despeito do tratamento. Dos 258 pacientes que alcançaram remissão inicialmente com o tratamento, 109 (42\%) apresentaram recidiva em um período médio de 44 meses. Dos 76 pacientes que se mostraram refratários ao tratamento, 60 desenvolveram insuficiência renal terminal em até dois meses de tratamento e 12 vieram a óbito ainda no primeiro mês de seguimento. Os fatores associados de maneira independente à refratariedade foram sexo feminino, etnia negra, apresentação da doença já com insuficiência renal, avaliação histológica com maiores índices de cronicidade e esclerose vascular e o não-uso de ciclofosfamida, ou seja, pacientes que receberam apenas corticóide como tratamento apresentaram maior chance de progressão da doença. No que diz respeito à recidiva, pacientes com anticorpo antiproteinase 3 apresentaram maior chance de recidiva ( $1,8 \mathrm{vez})$ em comparação aos pacientes com antimieloperoxidase. O envolvimento de trato respiratório superior ou inferior também aponta maior chance de recidiva. Esse trabalho reafirma alguns pontos de importância na abordagem desses pacientes: i) vasculites associadas ao Anca são doenças potencialmente graves; ii) o tratamento de indução deve incluir imunossupressores, notadamente ciclofosfamida; e iii) a despeito de se alcançar remissão com o tratamento inicial, o risco de recidiva é alto. Outra contribuição importante desse estudo é apontar que características como a positividade para antiproteinase 3 e o envolvimento pulmonar podem sugerir que pacientes estão sob maior risco de recidiva. No entanto, para sua utilização em decisão terapêutica, esses dados devem ser confirmados em estudos prospectivos. 
Pagnoux C, Mahr A, Cohen P, Guillevin L: Presentation and outcome of gastrointestinal involvement in systemic necrotizing vasculitides: analysis of 62 patients with polyarteritis nodosa, microscopic polyangiitis, Wegener's granulomatosis, ChurgStrauss syndrome, or rheumatoid arthritis-associated vasculitis (Apresentação e evolução de envolvimento gastrointestinal em vasculites sistêmicas necrotizantes: análise de 62 pacientes com poliarterite nodosa, poliangiíte microscópica, granulomatose de Wegener, síndrome de Churg-Strauss e vasculite associada à artrite reumatóide). Medicine (Baltimore) 84: 115-28, 2005. Serviço de Medicina Interna do Hôpital Cochin, Paris, França.

Os autores avaliaram retrospectivamente os pacientes seguidos em seu serviço de referência quanto ao envolvimento gastrointestinal secundário às vasculites necrotizantes. Dor abdominal foi o sintoma mais comum, ocorrendo em $97 \%$ dos pacientes. Outros sintomas gastrointestinais, como náusea/vômitos, diarréia e exteriorização de sangramento, são menos freqüentes. Apenas um paciente apresentou envolvimento gastrointestinal como manifestação isolada de vasculite necrotizante. Estudos angiográficos mostraram sinais de vasculite em 26 (67\%) dos 39 pacientes avaliados, notadamente pacientes com poliarterite nodosa. A tomografia de abdômen mostrou alterações em $75 \%$ dos pacientes examinados, basicamente com evidência de peritonite. A avaliação endoscópica do trato gastrointestinal tanto superior quanto inferior foi capaz de mostrar úlceras aparentemente isquêmicas, mas o rendimento de biópsias endoscópicas para confirmação de vasculite foi pequeno - apenas três de 36 amostras mostraram evidência histológi- ca de vasculite. No entanto, avaliação histológica em peças cirúrgicas, como apêndice, vesícula biliar e segmentos de intestino delgado ou cólon ressecados por isquemia, apresentou maior sensibilidade, tendo sido possível a confirmação de vasculite na maior parte das amostras. Dos pacientes analisados, 16 (26\%) evoluíram para óbito. Manifestações mais graves como peritonite, isquemia intestinal e oclusão intestinal são associadas a um pior prognóstico. Ainda que menos freqüente do que envolvimento respiratório ou renal, o comprometimento do trato gastrointestinal é relativamente freqüente em vasculites sistêmicas e capaz de influenciar a sobrevida desses pacientes. No entanto, o prognóstico dos pacientes mais graves melhorou bastante nas últimas décadas pela otimização dos procedimentos diagnóstico e terapêutico, seja a abordagem cirúrgica pronta quando indicada ou a associação de corticóide e imunossupressores em tratamento clínico.

Sablé-Fourtassu R, Cohen O, Mahr A, et al: Antineutrophil Cytoplasmic Antibodies and the Churg-Strauss Syndrome (Anca e síndrome de Churg-Strauss). Ann Intern Med 143: 632-8, 2005. Grupo Francês de Estudo das Vasculites, França.

Síndrome de Churg-Strauss é uma forma rara de vasculite de vasos de pequeno calibre. Usualmente se desenvolve em pacientes com história de asma. A síndrome se caracteriza clinicamente pelo envolvimento pulmonar e manifestações extrapulmonares que podem ser graves e potencialmente fatais, como miocardite, glomerulonefrite e isquemia do trato gastrointestinal. Até dois terços dos pacientes podem apresentar Anca. Nesse trabalho, os autores avaliaram em uma coorte homogênea $(\mathrm{n}=112)$ as principais características demográficas, clínicas e laboratoriais de acordo com a presença do Anca. Nesse grupo de pacientes, 43 (38\%) apresentaram Anca positivo, sendo $39 \mathrm{em}$ seu padrão perinuclear (P-Anca) e quatro em seu padrão citoplasmático (C-Anca). Dos 39 pacientes com padrão P-Anca, 34 apresentaram anticorpo antimieloperoxidase na análise por ELISA.
Nos outros pacientes, não foram encontrados antimieloperoxidase ou antiproteinase 3. Outros antígenos não foram testados. Em comparação aos pacientes Anca negativos, os pacientes Anca positivos apresentaram maior freqüência de envolvimento renal $(35 \%$ vs. $4 \%) \mathrm{e}$ neuropatia periférica ( $84 \%$ vs. $65 \%)$. Os pacientes Anca negativos apresentaram maior freqüência de febre $(55 \%$ vs. $30 \%)$ e envolvimento cardíaco ( $49 \%$ vs. $12 \%)$. Não existiu associação entre o status do Anca e a resposta ao tratamento ou prognóstico. Esse trabalho sugere que pacientes com síndrome de Churg-Strauss podem apresentar fenótipo diferente de acordo com a positividade do Anca. O melhor entendimento dos mecanismos fisiopatológicos associados a marcadores imunológicos como o Anca pode vir a ser de valia na abordagem terapêutica estratificada desses pacientes. 